\title{
David Oliver: Hip fracture care shows the way
}

\author{
David Oliver consultant in geriatrics and acute general medicine
}

Berkshire

The NHS increasingly emphasises safety, quality, and value, using data on variations to improve practice and outcomes and developing clinically led collaborative models of care. ${ }^{12}$ But is this delivering?

Improvements in the care of people with hip fractures show just what can be achieved. ${ }^{3}$ Patients are typically over 80 , frail, and multimorbid, with falls and fragile bones. Cognitive and functional impairments are common. Mortality rates after surgery are high. ${ }^{4}$

Patients with hip fractures weren't traditionally viewed as the glamorous end of trauma surgery. They often waited several days for surgery, which was often cancelled in favour of other more interesting cases, or were operated on late at night by junior teams. ${ }^{5}$ Older, frailer patients are harmed by avoidable prolonged bed rest and admission to hospital. Delays to surgical fixation can worsen outcomes and pain control and prevent prompt mobilisation. ${ }^{6}$

The Scottish Hip Fracture Audit lit the path. ${ }^{7}$ Then, in 2007, the British Orthopaedic Association and British Geriatrics Society published the Blue Book, ${ }^{8}$ setting standards of care for older people with fragility fractures. The momentum continued with the creation of the National Hip Fracture Database, which now includes all 180 eligible hospitals in England, Wales, and Northern Ireland and registers over 95\% of all hip fractures. ${ }^{3}$

The Department of Health got involved, with a national falls and fractures programme, ${ }^{5}$ and it created a national tariff for best practice, where hospitals would be fully reimbursed for each case of hip fracture only if they met the following audit standards: (a) admission under consultant led joint orthopaedic-geriatric care; (b) multidisciplinary assessment protocol on admission; (c) surgery within 36 hours; (d) geriatrician review within 72 hours; (e) geriatrician-led multiprofessional rehabilitation; and (f) assessment for falls and bone protection. ${ }^{35}$

Process improvements include faster admission, more prompt pain relief and fluids, more daytime surgery by senior teams, and shorter stays

Clinically driven and owned standards, government backing, transparent national reporting of data (who wants to be an outlier?), financial incentives for quality, and regular regional and national meetings for peer support and learning meant that more hospitals adopted specialist, interprofessional "orthogeriatric" models of care.

Patients have benefited. Process improvements include faster admission, more prompt pain relief and fluids, more daytime surgery by senior teams, and shorter stays. ${ }^{3}$ Many individual units have reported major improvements. ${ }^{9}{ }^{10}$ From 2007 to 2011 the 30 day hip fracture mortality in audited hospitals fell by 28\%. ${ }^{11}$ Time series analysis of 33000 patients in 11 hospitals over 10 years showed reductions in 30 day mortality (down $27 \%$ ) and one year mortality (down 19\%) associated with the introduction of orthogeriatrics models. ${ }^{12}$

This successful approach developed by the NHS has been adapted and adopted in several countries. If it can work for people with broken hips, what's stopping us doing it for many other conditions?

Competing interests: See www.bmj.com/about-bmj/freelancecontributors/david-oliver.

Provenance and peer review: Commissioned; not externally peer reviewed.

NHS England. Right Care programme (ongoing). www.rightcare.nhs.uk/.

2 NHS England. New Models of Care programme (ongoing). https://www.england.nhs.uk/ 2015/01/models-of-care/.

3 National Hip Fracture Database. 2015 annual report. www.nhfd.co.uk/2015report. 4 National Institute for Health and Care Excellence. NICE guideline CG124: hip fracture management. 2011; updated 2014. https://www.nice.org.uk/guidance/cg124.

5 Oliver D, Willett K. Falls, fragility and fractures: lessons from the last decade and opportunities for the next. Osteoporosis Review 2011;19:7-12.

6 Simunovic N, Devereaux P, Bhandari M. Surgery for hip fracture: does surgical delay affect outcomes? Indian J Ortho 2011;45:27-32. www.ncbi.nlm.nih.gov/pmc/articles/ PMC3004074/.

7 National Osteoporosis Society. Measuring services: the Scottish Hip Fracture Audit. https: //www.nos.org.uk/about-us/public-affairs/assessing-services/scotland.

8 British Orthopaedic Association, British Geriatrics Society. The blue book: the care of patients with fragility fracture. Sep 2007. www.fractures.com/pdf/BOA-BGS-Blue-Book. pdf.

9 Chamberlain M, Pugh H. BMJ quality improvement programme: improving the quality of hip fracture care with the introduction of a hip fracture pathway. BMJ Qual Improv Report 2015;4. doi:10.1136/bmjquality.u204075.w2786.

10 Gupta A. The effectiveness of geriatrician-led comprehensive hip fracture collaborative care in a new acute hip unit based in a general hospital setting in the UK. $J R$ Coll Physicians Edinb 2014;44:20-6. doi:10.4997/JRCPE.2014.105 pmid:24995442.

11 Neuburger J, Currie C, Wakeman R, et al. The impact of a national clinician-led audit initiative on care and mortality after hip fracture in England: an external evaluation using 
time trends in non-audit data. Med Care 2015;53:686-91. doi:10.1097/MLR 0000000000000383 pmid:26172938.

12 Hawley S, Javaid MK, Prieto-Alhambra D, et al. Effectiveness of orthogeriatric and fracture liaison service models. Age Ageing2016;45:236-42.
Published by the BMJ Publishing Group Limited. For permission to use (where not already granted under a licence) please go to http://group.bmj.com/group/rights-licensing/ permissions 